International Journal of Engineering \& Technology, $7(1.3)(2018)$ 130-132
International Journal of Engineering \& Technology
SPC
Website: www.sciencepubco.com/index.php/IJET
Research paper

\title{
An effective method for preventing chain from snatching
}

\author{
M.Prakash ${ }^{1}$, K. Nandhini ${ }^{1 *}$, K. Narmatha ${ }^{1}$, SV. Swetha ${ }^{1}$, J.Srikanth ${ }^{2}$ \\ ${ }^{l}$ Department of Computer Science and Engineering, Karpagam College of Engineering, Coimbatore, India. \\ ${ }^{2}$ Department of Computer Science and Engineering, Sasurie College of Engineering, Vijayamangalam, India. \\ "Corresponding author: nandhukk28@gmail.com
}

\begin{abstract}
Chain snatching is a serious threat scaring the public and a challenging issue for the police department to trace the offenders and recover the gold. To resolve this issue, the city police installed CCTV cameras and organized awareness programmes in crowdy places. These initiatives reduced the crime to certain extent. However, things remain the same and chain snatching has considerably increased. As offenders usually target the women in the society, it is very difficult to recover emotionally the affected women by such incidents. In this paper, it is proposed to design a small electronic gadget to track continuously when the chain is snatched. This gadget uses power from the human body, wearable sensors to track the location, and wireless transmission technology with smart phones over long distances. This innovative design will reduce the anti-social activities in public places. It can also be used as a life saver during accidents in remote areas.
\end{abstract}

Keywords: Gadget; Internet of Thing; Chain Snatching; ARM processor; ZIGBEE; GPS tracker; Raspberry Pi.

\section{Introduction}

There are many sensational news about chain snatching in daytoday life. The Snatchers target women by making sudden attacks at the crowdy places like shopping malls, residential areas, markets etc. After the chain has been snatched, it is not an easy way to identify the snatcher(burglar). Often it is read in the newspapers about the chain snatching incidents and it creates a negative impact in the society.Fig 1 describes the incident related to chain snatching.

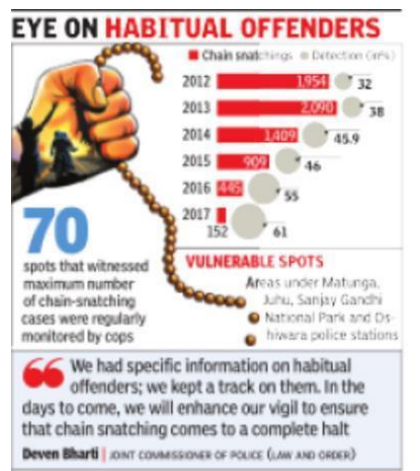

Fig 1:Images related to Chain Snatching.

To Resolve the problem of chain snatching, the police department monitors the activities of robbers on a daily basis and make the city under surveillance intensively. Moreover, undetected chain snatching instances are resolved with the help of CCTV footages available on public places, malls, super market business areas etc. Despite the efforts made by the cops, the instances of chain snatching had not come down.
With these issues, this project fixes its goal to have an innovative design for developing a smart electronic gadget with a combined technology of tracking the offender by transmitting signals through wireless transmission to the police department.

\section{Background and Related work}

The chain snatchers employ rob-and-run tactics. Hence, there is a need to take action immediately with the support of police department to apprehend the robbers.The snatch theft alarm system was developed using the RF signal (Wan Omar, 2007). It uses two circuits, one with siren and receiver unit and other with the transmitter unit. The transmitter unit uses RF signal to control the siren. Yet the device is limited to a certain range and does not uses rechargeable battery.

The ultrasonic sensor (Ahmad Yasser, 2014) is clipped in the handbag handle and when snatching happens, this handle will be snapped and fall in the ground and signals the alarm. But, if the handle by mistake is near the ground, then it starts ringing and it is not user-friendly.

The alarm system based on an audio mono jack plugged into a socket connected to a circuit inside the handbag (Muhsin, 2010). The audio mono jack is attached to the necklace and activates the alarm when the handbag is snatched. This work has a limitation that there is a need to always wear the necklace.

The Device which is used to track the vehicle using Global System for Mobile (GSM) and Global Positioning System(GPS) tracker was designed by Maurya.K ,Singh.M , and Jain.N (2012) which is used to track the theft vehicle. 


\section{Proposed Work}

The proposed work involves the design and development of an electronic gadget that records the criminal offence of chain snatching automatically and the recorded scenario gets transmitted to the nearby police station to alert them and have an immediate action.

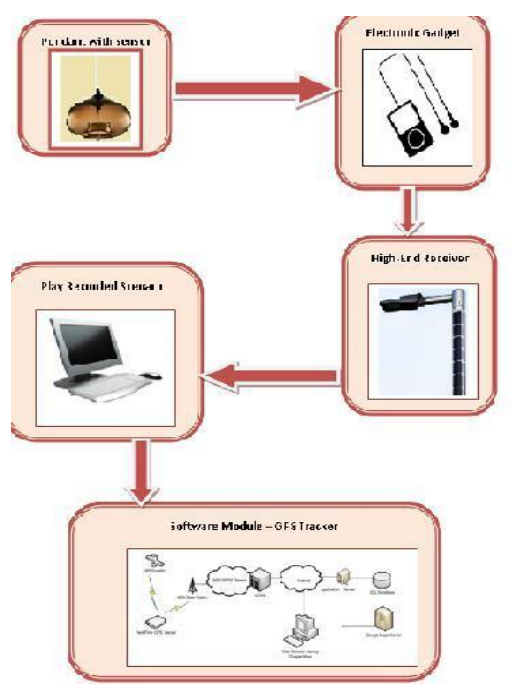

Fig 2: Workflow of Proposed System

As an initial step, a sensor has to be attached to the pendant of the chain. The sensor that is more apt with fast responsive ability is force sensor. This gets activated when external force is applied to the pendant. This external force generates a vibration. The vibration is transmitted to the electronic gadget. The below figure (Fig 3) shows the pendant with Z-Force sensor.

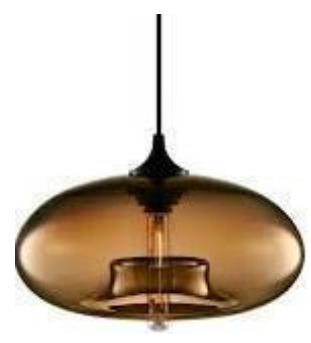

Fig 3: Pendant embedded with Force sensor

This force sensor is thin size $(0.5 \mathrm{~mm})$, cheap and shock resistive in nature. The information sensed need to be processed and there is a need of electronic gadget.The design of the electronic gadget is shown in the Fig 4.

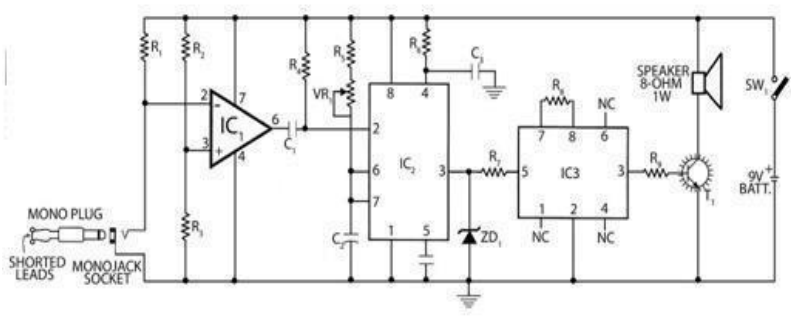

Fig 4: Circuit diagram for alarm.

Figure 3 is referred from the reference work done by Tesis Sarjana Muda's “Anti Snatch Alarm System”(Reference 13). The circuit includes an operational amplifier IC CA3140 (IC1), configured as a comparator. The two inputs (inverting and non - inverting) of the circuit is given to pin no 3 and 2 of the operational amplifier respectively and output is obtained from pin no 6 . The circuit also include a monostable multivibrator, IC2 (timer IC NE555). The timer controls included in the circuit are R5, VR1, and capacitor $\mathrm{C} 2$ with the given value in this circuit diagram lets the time of timer is about 1 minute. The other component, IC3 is used as alarm tone generator with an inbuilt oscillator for audio recording. At the final process the output is achieved through IC 3 of pin no 3 and by the use of transistor T1 its get amplified to reach the desire level and fed as the input to the loudspeaker for the output. At the moment when the theft occurs, an emergency signal gets transmitted by the RF transmitter to the nearest smart gadget that is made available in the direction of the motion of the culprit. The electronic gadget gets triggered and can track down the culprit.The public end device is located at the lamp post then transmits the information to the nearest police control room using wireless sensor technology. This receiver is interfaced with mobile and computer system.

The framework of our project consists of Advanced RISC Machine(ARM) Processor, Raspberry pi and ZigBee. These are the main components of working system. Advanced RISC Machine(ARM) Processor is a set of smaller sized computer instructions which operate at high speed. ARM Processor includes system-on-chips (SoC) and systems-on-modules(SoM) that incorporate memory, interfaces etc. It also designs some of the cores that implement this instruction set.Processors which have a Reduced Instruction Set Computing (RISC) architecture requires fewer transistors with a Complex Instruction Set Computing (CISC) architecture (such as the $\mathrm{x} 86$ processors found in most personal computers), which improves the power consumption, and heat dissipation.

Such characteristics are mostly desirable for portable and batterypowered devices - including Laptops,smartphones, tablet computers and other embedded systems .For supercomputers it will consume large amounts of electricity and that of ARM could also be a power-efficient solution.It support a 32-bit address space, 32-bit arithmetic instructions and 32-bit fixed-length instructions, but later versions of the architecture also support a variable-length instruction set that provides both 32- and 16-bit instructions for improved code density. Before used cores can also provide hardware execution of Java Bytecodes. ARM Processor consists of Voltage Regulator,System Controller,Memory Controller,etc.Fig 5 defines the system architecture of ARM Processor.

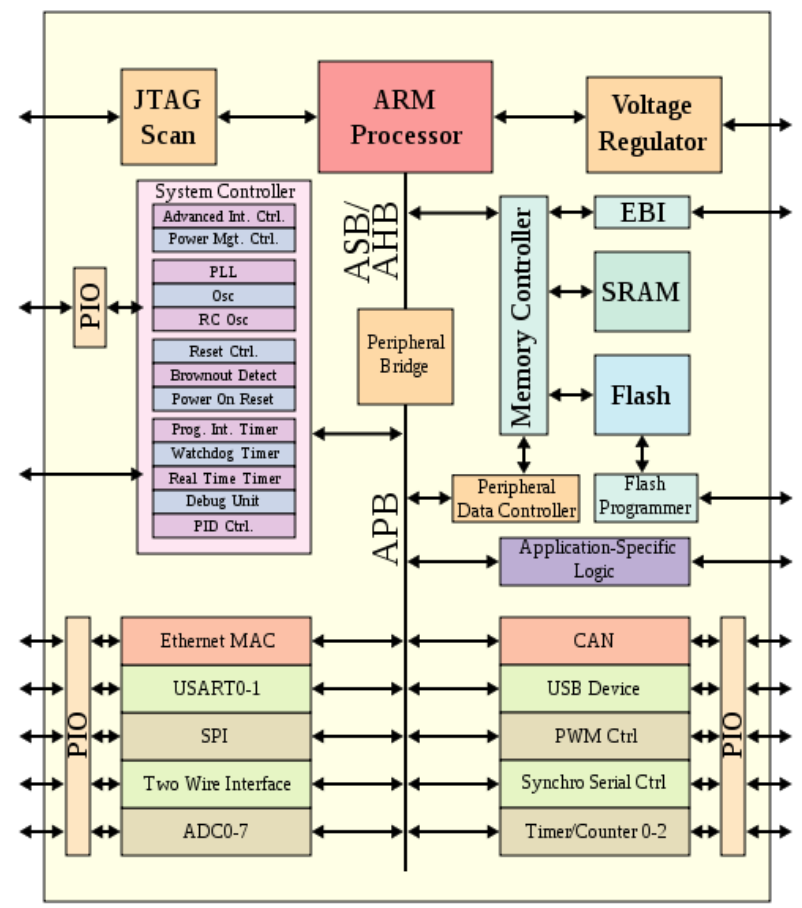

Fig 5: ARM Processor System Architecture. 
Zigbee is a low-cost and power,wireless mesh network standard targeted at battery-powered devices in wireless control and monitoring applications.It provides low-latency communication and are typically integrated with radios and with microcontrollers. Zigbee operates in the industrial, scientific and medical as (ISM) radio bands.It is built on the physical layer and media access control defined in IEEE standard for low-rate wireless personal area networks (WPANs).

The specification. includes four main components like Network layer, Application layer, Zigbee Device Objects (ZDOs) and manufacturer-defined application objects. ZDOs are responsible for some tasks like keeping track of device roles, managing requests to join a network, as well as device discovery and security etc.The Raspberry Pi is a series of small single board computers. All models feature a Broadcom system-on-chip (SoC) with an integrated ARM compatible Central Processing Unit (CPU) and 0n-chip graphics processing (GPU).

Fig 6 represents the Architecture of Raspberry Pi Processor .It's speed ranges from $700 \mathrm{MHz}$ to $1.2 \mathrm{GHz}$,on-board memory ranges from $256 \mathrm{MB}$ to $1 \mathrm{~GB}$ RAM. The Secure Digital (SD) cards are used to store the operating system .The boards have one to four USB ports,General Purpose Input Output pins(GPIO),Ethernet Port .

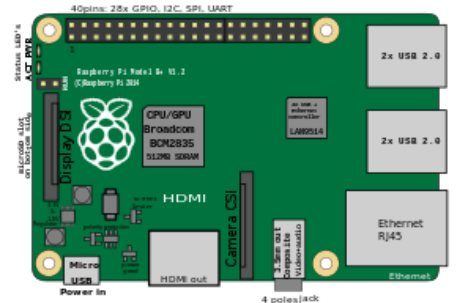

Fig 6: Architecture of of Raspberry Pi.

A software tool is designed in such a way that whenever an alert signal (notification) has been received by the receiver, it finds the location of crime and downloads the recorded video. And the identified location will be shared to the police control room. This helps the police in tracking the culprit within a short span of time.

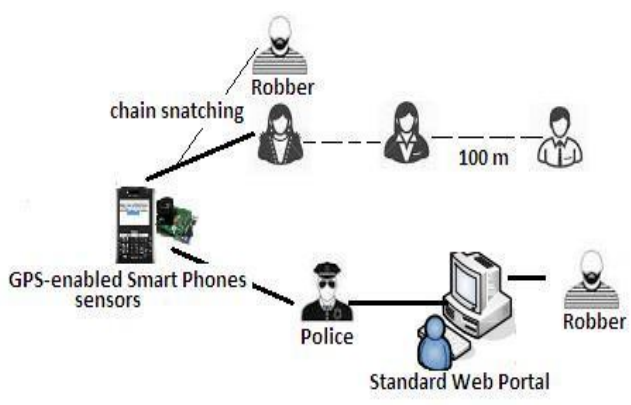

Fig 7: System Architecture

The software tool comprises of three components (i) a service provider, (ii) mobile device users and (iii) geosocial networks. The service provider analyses the publically available database related to crime of chain snatching, so that it can be used for further analysis. GPS enabled smart phones provides the geographic location of the incident. Smart phones can immediately connected to the social network to connect to the public. The web portal provides further information to track the set of routes and bus stop locations immediately. iSafe, a distributed algorithm is also used as it enables wireless capabilities of mobile devices in taking real time snapshots and collectively uses co-located users' profiles without using their private information.

\section{Conclusion}

A framework that uses electronic gadget with less power utilization containing sensors is designed to capture the instance of chain snatching. The captured information along with geographical information gathered from the GPS enable smart phones is transmitted using wireless technology to the nearest police station through SMS and a call. This innovative design will reduce the anti-social issues like chain snatching to certain extent.In future, alarm buzzers can be connected to this gadget to alert the entire surrounding immediately.

\section{References}

[1] Suo, H., Wan, J., Zou, C., \& Liu, J. (2012, March). Security in the internet of things: a review. In Computer Science and Electronics Engineering (ICCSEE), 2012 international conference on (Vol. 3, pp. 648-651). IEEE.

[2] Maurya, K., Singh, M., \& Jain, N. (2012). Real time vehicle tracking system using gsm and gps technology-an antitheft tracking system. International Journal of Electronics and Computer Science Engineering. ISSN, 2277-1956.

[3] Song, H., Zhu, S., \& Cao, G. (2008, April). Svats: A sensor-network-based vehicle anti-theft system. In INFOCOM 2008. The 27th Conference on Computer Communications. IEEE(pp. 2128-2136). IEEE.

[4] Ibrahim, V. M., \& Victor, A. A. (2012). Microcontroller based anti-theft security system using GSM networks with text message as feedback. International Journal of Engineering Research and Development, 2(10), 18-22p.

[5] Zhou, W., \& Piramuthu, S. (2014, June). Security/privacy of wearable fitness tracking IoT devices. In Information Systems and Technologies (CISTI), 2014 9th Iberian Conference on (pp. 1-5). IEEE.

[6] TongKe, F. (2013). Smart agriculture based on cloud computing and IOT. Journal of Convergence Information Technology, 8(2)

[7] Lee, S., Tewolde, G., \& Kwon, J. (2014, March). Design and implementation of vehicle tracking system using GPS/GSM/GPRS technology and smartphone application. In Internet of Things (WF-IoT), 2014 IEEE World Forum on (pp. 353-358). IEEE.

[8] Nalavade, V., Swami, N., Sutrave, S., \& Bobade, A. M. An Intelligent automobile Anti-Theft Tracking and Calamity Detection System Based on IoT using RASPBERRY PI For Real Time Applications.

[9] Khimani, H., \& Parekh, M. C. (2017). IoT Security and Hardware Implementation using DTMF 8870. International Journal, 8(5).

[10] Kaur, H., \& Malhotra, J. An IoTbased Smart Architecture for Traffic Management System.

[11] Hussain, G. J., \& Reddy, T. S. (2016). Advanced AntiTheft ATM Security using Raspberry Pi.

[12] NAGADEEP, G., \& RAO, K. S. S. ADVANCED ANTI THEFT ATM SECURITY SYSTEM WITH ZIGBEE AND GSM.

[13] M. Nizam, Wan. (2007). Anti Snatch Alarm System .Tesis Sarjana Muda.

[14] Muhsin, Azliza. 2010. Snatch Theft Alarm System. Tesis Sarjana Muda. Faculty of Electrical Engineering, Universiti Teknologi Malaysia, Johor Zakaria, I. Hazirah. 2012. Sistem

[15] Yaseer, Ahmad. 2014. Simple Arduino Ultrasonic Door Alarm Instructable Inc. 